\title{
Clinical Characteristics, Prognostic Factors, and Real-World Practice of Abnormal Liver Function Tests in Children with Acute Infectious Diseases: A Multicenter Study
}

\section{Kyung Jae Lee}

Hallym University Sacred Heart Hospital, Hallym University College of Medicine

\section{Dae Yong Yi}

Chung-Ang University Hospital, College of Medicine, Chung-Ang University

\section{Yoo Min Lee}

Soonchunhyang University Bucheon Hospital, Soonchunhyang University College of medicine

\section{So Yoon Choi}

Kosin Gospel Hospital, Kosin University College of Medicine

\section{You Jin Choi}

Inje University Ilsan Paik Hospital

\section{Yoon Lee ( $\square$ ragabash@korea.ac.kr)}

Korea University Medical Center Anam Hospital

\section{Research Article}

Keywords: liver function test, nonspecific reactive hepatitis, pediatrics

Posted Date: May 27th, 2021

DOl: https://doi.org/10.21203/rs.3.rs-533197/v1

License: (c) (1) This work is licensed under a Creative Commons Attribution 4.0 International License.

Read Full License 


\section{Abstract}

\section{Background}

Abnormal liver function tests (LFTs) are commonly seen in pediatric patients with acute infectious diseases; few studies and no definite clinical guidelines for these conditions are available. This study aimed to elucidate the causes and factors associated with prolongation of liver enzyme elevation. We also investigated actual real-world practices in Korea.

\section{Methods}

A retrospective study was performed on all patients younger than 18 years, who visited six tertiary teaching hospitals around Korea in 2018 for acute infectious diseases and showed alanine aminotransferase (ALT) levels above $60 \mathrm{lU} / \mathrm{L}$. We categorized the infections that cause LFT elevation into six groups: respiratory infection, gastrointestinal infection, urinary tract infection, other febrile disease, Epstein-Barr virus infection, and cytomegalovirus infection. We collected data on the medical specialty of the attending physician who followed up the subject, follow-up duration, percentage of follow-up loss, and their investigation.

\section{Results}

A total of 613 patients were enrolled in this study, half of whom (50.7\%) were younger than 12 months. The mean initial aspartate aminotransferase and ALT values were 171.2 \pm 274.1 and $194.9 \pm 316.1 \mathrm{IU} / \mathrm{L}$ (range 23 2881, 60 2949 IU/L), respectively; however, other LFTs were within the normal range. Respiratory infection was the most common diagnosis (45.0\%), and rhinovirus was the most commonly identified pathogen (9.8\%). The follow-up rate was higher with pediatric gastroenterologists $(90.5 \%)$ and non-gastroenterology pediatricians $(76.4 \%)$ than with pediatric residents and emergency doctors. Older age was related to better ALT recovery (odds ratio [OR] of age for month was 1.003 , with $95 \%$ confidence interval [Cl] 1.001-1.004, $p=0.004$ ), while the number of infection episodes (OR=0.626, 95\% $\mathrm{Cl}$ 0.505-0.777, $p<0.001)$ was associated with poor ALT recovery. Abdominal sonography was the most commonly used diagnostic tool (36.9\%), followed by the hepatotropic virus workup. The modalities of hepatitis workup were significantly differently applied by physicians based on their specialties and institutions.

\section{Conclusions}

An LFT abnormality after a systemic infection was common in respiratory infection and under the age of 1 year. Age, number of infections, and initial results of LFTs were related to ALT recovery time. Interphysician, inter-institution, and inter-specialty variances were observed in real-world practice.

\section{Background}

An abnormal liver function test (LFT) is commonly observed in pediatric patients with acute infectious diseases such as respiratory tract infections, gastroenteritis, and urinary tract infections $(1,2)$. Most 
patients only show modest aspartate aminotransferase (AST) and alanine aminotransferase (ALT) elevation; however, some patients might have more severe hepatic injuries showing other LFT abnormalities such as elevated bilirubin levels, prolonged prothrombin time, and hypoalbuminemia (1). Some pathogens, such as tuberculosis, Campylobacter, Clostridium perfringens, cytomegalovirus (CMV), and herpes virus could cause not only transient abnormal LFTs but also acute liver failure and hepatic encephalopathy (1). This condition is usually self-limiting; however, sometimes it can persist for longer than a year, which could annoy parents and physicians (2). The exact pathophysiology of liver involvement in systemic infection is not well known; it can induce hepatic injury through direct invasion, indirect toxin-induced injury, or cytokines (1).

Nonspecific reactive hepatitis (NRH) is defined as a nonspecific inflammatory process without any specific histologic finding suggestive of a specific liver disease $(3,4)$. NRH is usually used to refer to secondary liver injury due to extrahepatic disease without any primary cause of liver-specific disease. However, it is unclear which pathogen could be regarded as the cause of $\mathrm{NRH}$, from among those such as enterovirus, CMV, Epstein-Barr virus (EBV), herpes simplex virus (HSV), rotavirus, and respiratory syncytial virus, because they primarily evoke systemic infection and are known to be associated with liver injury (4). Although it should be confirmed through histology, due to the relatively mild clinical course of the disease and invasiveness of liver biopsy, we usually regard NRH as having no symptoms indicating hepatitis and showing elevation of liver enzymes in their blood test without any evidence of hepatotropic virus or other specific liver disease (4). Therefore, in clinical situations, it might be acceptable to consider $\mathrm{NRH}$ if there is no evidence of other specific causes and symptoms of hepatitis and the AST and ALT are elevated in acute infectious diseases.

To our knowledge, there are only a few studies and no clinical guidelines for the diagnosis and management of $\mathrm{NRH}$. We conducted a multicenter study to elucidate the cause of NRH and factors associated with prolongation of liver enzyme elevation, which are of concern to physicians. Furthermore, through this multicenter study, we might know the physician's approach to NRH in real-world practice in Korea.

\section{Methods}

A retrospective study was conducted on all patients younger than 18 years who visited any of the six tertiary teaching hospitals around Korea in 2018 for acute infectious diseases and showed ALT levels above $60 \mathrm{IU} / \mathrm{L}$. To identify subjects with NRH, we excluded patients with non-alcoholic fatty liver disease, hepatotropic virus infections, autoimmune disease, muscular disease, and other toxic hepatitis.

The number of infections during the period of elevated liver enzyme levels was measured; in cases with ALT recovery followed by recurrent ALT elevation above $60 \mathrm{IU}$ were defined as 'relapse of the LFT elevation'. We collected the results of initial LFTs such as AST, ALT, total bilirubin (TB), direct bilirubin (DB), alkaline phosphatase, gamma glutamyl transferase (GGT), albumin, white blood cell counts, and 
prothrombin time/international normalized ratio (PT/INR). We also collected the peak and final AST, ALT, TB, and DB levels.

We categorized the infections that cause LFT elevation into six groups: respiratory infection, gastrointestinal (GI) infection, urinary tract infection (UTI), other febrile disease, and EBV and CMV infection. We evaluated the etiology of the infection using culture, polymerase chain reaction, and rapid antigen testing.

To evaluate the actual practice for managing $\mathrm{NRH}$, we collected data on the medical specialty of the attending physician who followed up the subject, as well as those on follow-up duration, percentage of follow-up loss, and the investigation of $\mathrm{NRH}$. We defined the follow-up group as the patients undergoing repetition of the LFT, and the follow-up loss group as the patients who underwent only one LFT, although the ALT level was above $60 \mathrm{IU} / \mathrm{L}$. We grouped physicians into five groups: non-GI pediatricians, pediatric gastroenterologists, pediatric residents, and emergency doctors. We evaluated hepatitis workup, such as radiologic examination, viral markers, and metabolic screening, according to physician groups and institutions. We evaluated the frequencies of tests such as those involving hepatitis B surface antigen, antibody, and other antibodies or polymerase chain reaction for hepatitis $A$ virus, hepatitis $C$ virus, EBV, CMV, toxoplasma, and HSV for infectious workup. We also checked the number of metabolic tests, such as the neonatal screening test, serum and/or urine amino-acid, organic acid, and ceruloplasmin for metabolic disease and fluorescent antinuclear antibody (FANA) for autoimmune disease.

\section{Statistics}

Statistical analysis was performed using the SPSS 20.0 statistical program software (IBM Corp. Armonk, NY. USA). Descriptive statistics for continuous variables are presented as mean \pm standard deviation (SD) or median with interquartile range (IQR) according to their distribution. Categorical variables were presented as frequencies and percentages. Analysis of the differences between categorical variables was performed using the chi-square test. Based on the distribution of the variables, the t-test and MannWhitney test were conducted to compare the means between the groups. To investigate the factors associated with ALT recovery time (time to ALT $<60 \mathrm{IU}$ ), the Cox proportional-hazards model was used. A $P$ value $<0.05$ was considered statistically significant.

\section{Results}

\section{Baseline characteristics}

A total of 613 patients were enrolled from six tertiary teaching hospitals in Korea. There were 367 (59.9\%) boys and $246(40.1 \%)$ girls, and the mean age was $3.49 \pm 5.17$ years. Half of our patients $(n=311$, $50.7 \%$ ) were younger than 12 months. The mean number of episodes of infection was 1.2 (range, 1-5), and $17(2.8 \%)$ patients experienced relapse of LFT elevation. The mean follow-up duration was $37.6 \pm 74.3$ (range 1-486) days (Table 1). About one-third ( $n=213,34.7 \%)$ of the patients confirmed that they had one or more siblings and 121 (19.7\%) patients had no siblings. 
The mean values of LFTs were as follows; initial AST 171.2 \pm 274.1 (range 23-2881) IU/L, initial ALT 194.9 \pm 316.1 (range 60-2949) IU/L, peak AST 198.1 \pm 300.6 (range 28-2881) IU/L, peak ALT 235.1 \pm 355 (range 60-2949) IU/L, final AST 60.6 \pm 49.5 (range 7-601) IU/L, and final ALT 72.5 \pm 77.4 (range 9-818) IU/L. However, the peak mean TB and DB were not elevated (Table 1). The PT/INR values were collected in $188(30.7 \%)$ patients over the follow-up period and the median value was 1.07 (IQR 1.0-1.16). Five patients $(0.82 \%)$ showed moderate coagulopathy (PT/INR $>1.5)$, including 2 with severe coagulopathy $(0.33 \%, \mathrm{PT} / \mathrm{INR}>2.0)$; however, none of them had other signs or symptoms of liver failure.

\section{Infection focuses and pathogens}

Respiratory infection was the most common diagnosis ( $n=276,43.5 \%)$, followed by unspecified febrile illness ( $n=116,18.3 \%)$, GI infection ( $n=111,17.5 \%)$, and UTI ( $n=90,14.2 \%)$ (Table 1). The mean follow-up duration was longest in CMV infection (133.6 \pm 91.2 days, range $21 \sim 255$ days) following UTI (48.4 \pm 86.3 days, range 1 383 days) and GI infection (39.5 78.0 days, range 1 477days). In microbiologic and serologic studies, 385 pathogens were identified; however, laboratory evidence of specific pathogens could not be identified in 291 subjects (47.5\%). Among the 322 microbiologic/serologic study-positive cases, 56 children (17.4\%) had positive results for more than one pathogen. Rhinovirus was the most commonly identified pathogen ( $n=60,9.8 \%)$, followed by respiratory syncytial virus $(n=57,9.3 \%)$, Escherichia coli $(n=55,9 \%)$, EBV $(n=46,7.5 \%)$, and adenovirus $(n=30,4.9 \%)$ (Table 2). Regarding the median follow-up duration according to the known specific pathogen, CMV infection showed the longest duration (median 53 days, IQR 12.5-160 days), followed by norovirus (median 32 days, IQR 4-63 days) and parainfluenza virus (median 14.5 days, IQR 1-60.5 days) (Table 2).

\section{Comparison between follow-up or follow-up loss groups}

Although most patients ( $n=442,72.1 \%)$ visited more than twice, approximately a quarter $(n=171,27.9 \%)$ of the patients did not (Table 3). The mean follow-up duration of the follow up group was $50.9 \pm 80.9$ (range 2-486) days. Among those who failed to follow-up, the follow-ups of 108 (23.5\%) patients were discontinued by physicians. (by non-GI pediatricians $(n=60)$, pediatric gastroenterologists $(n=8)$, pediatric residents $(n=2)$ and emergency doctors $(n=38)$ ).

Follow-up rates and loss rates differed significantly among the attending doctors $(p<0.001)$. Better compliance was observed in non-GI pediatricians and pediatric gastroenterologists (follow-up rates were $76.4 \%$ and $90.5 \%$, respectively). However, the patients of pediatric residents and emergency doctors showed much poorer compliance; the follow-up loss rates were as high as $77.8 \%$ and $85.7 \%$, respectively. Mean initial AST, ALT, and TB levels were significantly higher in the follow-up group (Table 3).

\section{Factors related to ALT recovery}

According to the univariate analysis, many variables were related to ALT recovery, such as number of infections, relapse, initial AST, ALT, TB, peak AST, ALT, and TB. However, after multivariate analysis, older age was associated with better ALT recovery (odds ratio (OR) of age for month was $1.003, p=0.004$ ), 
while the number of infection episodes $(\mathrm{OR}=0.626, p<0.001)$ was associated with poor ALT recovery. We also observed that higher initial ALT and TB were related to poor prognosis, although they were not statistically significant ( $\mathrm{OR}=0.999, \mathrm{OR}=0.791, p=0.12$, and $p=0.08$, respectively). Regarding clinical diagnosis, respiratory infection, UTI, and EBV infection were related to unfavorable prognosis for ALT recovery (Figure 1).

\section{Hepatitis workup}

Abdominal sonography was the most commonly used diagnostic tool for hepatitis $(n=226,36.9 \%)$, while abdominal computed tomography (CT) was rarely used $(n=17,2.8 \%)$. Hepatotropic viruses including hepatitis $B(n=190,31 \%)$, hepatitis A ( $n=161,26 \%)$, and hepatitis C $(n=148,24.1 \%)$ were usually screened. The other infectious markers used for hepatitis workup included EBV $(n=139,22.7 \%), C M V(n=99,16.2 \%)$, HSV $(n=68,11.19 \%)$, rubella $(n=45,7.3 \%)$, and toxoplasma $(n=41,6.7 \%)$. In terms of metabolic and autoimmune screening tests, neonatal screening tests $(n=10,1.6 \%)$, serum amino acids $(n=10,1.6 \%)$, urine organic acids $(n=11,1.6 \%)$, ceruloplasmin $(n=62,10.1 \%)$, and FANA $(n=50,8.2 \%)$ were evaluated.

Pediatric gastroenterologists more frequently used diverse diagnostic modalities than non-GI pediatricians: abdominal sonography ( $57.9 \%$ vs. $34.9 \%)$, and antibodies against hepatitis B $(50.0 \%$ vs. $28.9 \%)$, hepatitis A ( $42.1 \%$ vs. $25.1 \%)$, hepatitis C ( $40.5 \%$ vs. $21.4 \%)$, ceruloplasmin $(28.6 \%$ vs. $5.8 \%)$, and FANA ( $20.6 \%$ vs. $5.5 \%$ ) (Figure $2 A$ ). Less than $20 \%$ of emergency doctors and pediatric residents also performed diagnostic hepatitis workup. In addition to the difference among physicians for hepatitis workup, hospital-specific differences were also observed among tertiary hospitals in Korea (Figure 2B). These differences among physicians were statistically significant $(p<0.05)$, except for abdominal CT.

\section{Discussion}

Systemic infection-related liver enzyme elevation in children is a common clinical situation $(2,4)$. Although hepatic enzymes are increased in various diseases such as sepsis, respiratory infections, digestive diseases, and urinary tract infections, the clear mechanism of liver injury after systemic infection is still unknown (1). In addition, there is no clinical guidelines, and there are only a few studies about these conditions, follow-up interval, period, and diagnostic modalities that vary widely among doctors and institutions. The purpose of this study was to investigate the clinical characteristics of LFT elevation after systemic infection and the management by doctors and hospitals in the real world in Korea.

In the present study, ALT levels in some patients were elevated above $2000 \mathrm{IU}$, which is 50 times higher than the normal reference range, but none of them progressed to hepatic failure or had other signs of severe hepatic damage such as severe hyperbilirubinemia, clinically significant coagulopathy, or hepatic biosynthesis/clearance defects. Considering the inclusion and exclusion criteria of this study, these findings are natural. However, it is noteworthy that ALT can be elevated to the extent that severe hepatic pathologies are suspected, even in non-specific benign conditions. 
Respiratory infection was the most common diagnosis, and rhinovirus was the most common pathogen in our study. Previous Korean studies also reported that respiratory infection was the most common infection focus in $\mathrm{NRH}$; however, adenovirus and respiratory syncytial virus were more common than rhinovirus $(2,4)$. Some case reports also show that these respiratory viruses can cause liver injury during systemic infection (5-10). In addition to viruses, bacterial pneumonia (e.g., Streptococcus pneumonia, Haemophilus influenza, Staphylococcus aureus, or Pseudomonas aeruginosa) and mycoplasma pneumonia can cause hepatocellular damage and cause laboratory abnormalities, including hyperbilirubinemia (1). Similar to several previous reports, we found that GI (18.1\%) and UTI (14.7\%) were also common causes of $\mathrm{NRH}(2,4)$. One small pediatric study showed the relationship between reactive hepatitis and gastrointestinal infection, and rotavirus infection was associated with significantly higher transaminase levels than the infection with the norovirus or adenovirus group (11). However, in our study, adenovirus was more common than other GI pathogens. In terms of UTI, a previous Korean study reported that $20.5 \%$ of patients had elevated liver enzyme levels during urinary tract infection and the liver enzyme levels became normal within 1 month, except in one of 249 cases (12). However, in the current study, the mean follow-up duration of 90 patients with UTI was $48.4 \pm 86.3$ days, and Escherichia coli infection showed a somewhat longer duration (median, 13 days; IQR, 4-44 days) of ALT elevation than the previous study. This difference was probably due to the different study designs and study populations.

We found that the older age of patients was related to a shorter duration of hepatic enzyme elevation; the mean age of our study patients was 3.5 years, and 311 (50.7\%) were younger than 12 months. Other studies have also shown that children younger than 5 years commonly experience increased liver enzyme levels during systemic infections $(4,5,8,11,12)$. As the exact mechanism of $\mathrm{NRH}$ remains unknown, the explanation of the poorer prognosis in younger infants is even more difficult. In terms of the mechanism of $\mathrm{NRH}$, Polakos et al. suggested that the formation of inflammatory foci, including apoptotic hepatocytes, antigen-specific CD $8+T$ cells, and Kupffer cells might be related to the 'collateral damage' of the liver in many extrahepatic viral infections (7). In bacterial infection with/without septic conditions, the interaction between Kupffer cells, hepatocytes, neutrophils, and endothelial cells in response to systemic infection is thought to result in hepatic dysfunction $(13,14)$. Assuming the above-mentioned mechanism, poorer prognosis in young infants may be related to different hepatic immune functions and/or different hepatic functional reservoirs in younger children; however, we have failed to find supporting evidence.

A considerable number of patients $(n=108,17.6 \%)$ discontinued follow-up without LFT normalization, according to the physicians' decisions in this study. Most of them were seen by pediatricians and emergency doctors. Furthermore, the hepatitis workup was also significantly different between physicians and hospitals. Pediatrician and pediatric gastroenterologists usually repeat the LFT and perform hepatitis workup, such as sonography and tests involving other viral markers, more frequently than other doctors. This difference might be related to differences in clinical concerns due to their specialized medical fields and/or experiences and knowledge of liver diseases. Such generalist-specialist differences are not rare in many diseases (15-17). 
Inborn errors of metabolism are also associated with liver dysfunction and jaundice in young children. In many cases, an LFT abnormality is the earliest sign of such diseases; therefore, proper evaluation and treatment are required to avoid undesirable outcomes (18). However, in our study, only a few patients $(1.6 \%)$ underwent metabolic studies, even by pediatric gastroenterologists. Similar to the absence of cases with liver failure mentioned previously, this result might be related to the inclusion and exclusion criteria of the current study. Therefore, this could not reflect the actual number of metabolic screenings for pediatric LFT elevation. The clinical importance of metabolic screening cannot be overlooked. More attention toward metabolic diseases might be required to some extent.

When we encounter children with abnormal LFTs, we should consider various reasons for hepatitis in children, including infectious, toxic, metabolic, autoimmune, and others $(19,20)$. There are some review articles suggesting that we should repeat LFTs, including AST, ALT, GGT, and creatinine phosphokinase, if there is a persistent increase in liver enzyme levels; it suggested a stepwise approach to evaluate the etiology (20). It also suggested that the first-line panel should consist of liver ultrasonography and other frequent causes such as a hepatotropic virus and ceruloplasmin ( $>3$ years). Second-and third-line investigations should be considered to exclude autoimmune hepatitis and other metabolic diseases, including liver biopsies (20). However, it remains unclear when children have only mild transaminase elevation with a recent infection, because we should consider the cost-benefit effect, risk of recurrent vein puncture, and delayed diagnosis. We need to thoroughly review the patient's history, physical examination, and laboratory results to evaluate the timely and correct diagnosis of reactive hepatitis in children.

The limitations of this study are as follows. This was a retrospective study, and we collected data from six tertiary teaching hospitals, which might not reflect nationwide Korean data. However, through a multicenter study, we could determine the clinical characteristics, associated etiology, prognosis, and hepatitis workup for LFT abnormalities after a systemic infection. We reported real-world data on the differences among physicians and institutions in hepatitis workup under these conditions. This could be explained by the lack of evidence in this field, although it is a common clinical situation, especially in the pediatric field. Further studies on the etiology, mechanism, and prognosis of NRH are needed to establish consistent guidelines.

\section{Conclusions}

An LFT abnormality after systemic infection was common in respiratory infection and under the age of 1 year. Age, number of infections, and initial results of LFTs were significantly associated with ALT recovery time. Inter-physician, inter-institution, and inter-specialty variances were observed in real-world practice. Therefore, the development of standardized clinical guidelines for the diagnosis and treatment of $\mathrm{NRH}$ should be considered for appropriate and consistent management.

\section{Abbreviations}


LFT: liver function test

AST: aspartate aminotransferase

ALT: alanine aminotransferase

CMV: cytomegalovirus

$\mathrm{NRH}$ : nonspecific reactive hepatitis

EBV: Epstein-Barr virus

HSV: herpes simplex virus

TB: total bilirubin

DB: direct bilirubin

GGT: gamma glutamyl transferase

PT/INR: prothrombin time international normalized ratio

Gl: gastrointestinal

UTI: urinary tract infection

FANA: fluorescent antinuclear antibody

SD: standard deviation

IQR: interquartile range

OR: odds ratio

CT: computed tomography

\section{Declarations}

\section{Ethical approval}

All institutional review boards (IRBs) of the six hospitals approved the study. And all the IRB provided waiver of informed consent for clinical investigations involving no more than minimal risk to human subjects. (Hallym University Sacred Heart Hospital Institutional Review Board / Ethics Committee (IRB no. 2019-04-022), Korea University Anam Hospital Institutional Review Board (IRB no. 2020AN0123), Institutional Review Board of Chung-Ang University Hospital (IRB no. 1812-020-16236), Soonchunhyang University Bucheon Hospital / Institutional Revuew Board (IRB no. 2019-07-021-004), Inje University Ilsan 
Paik Hospital Institutional Review Board (IRB no. 2019-09-012), Inje University Haeundae Paik Hospital Institutional Review Board (IRB no. 2019-07-021))

All methods were carried out in accordance with relevant guidelines and regulations. The research was performed in accordance with the Declaration of Helsinki. All authors agree with the contents of the manuscript.

\section{Consent for publication}

Not applicable.

\section{Availability of data material.}

The datasets used and/or analysed during the current study are available from the corresponding author on reasonable request.

\section{Competing interests}

None of the authors have any competing interest to declare

\section{Funding}

Not applicable.

\section{Author's Contributions}

Kyung Jae Lee and Yoon Lee wrote the main manuscript text, performed the statistical analysis, and interpreted the data. Dae Yong Yi, Yoo Min Lee, So Yoon Choi, and You Jin Choi collected the clinical data and reviewed the manuscript. All authors read and approved the final manuscript.

\section{Acknowledgements}

We would like to thank Editage for English language editing.

\section{References}

1. Minemura M, Tajiri K, Shimizu Y. Liver involvement in systemic infection. World J Hepatol. 2014;6:632-42.

2. Jang M, Oh MS, Oh SC, Kang KS. Distribution of Diseases Causing Liver Function Test Abnormality in Children and Natural Recovery Time of the Abnormal Liver Function. J Korean Med Sci. 2016;31:1784-9.

3. Schaffner F, Popper H. Nonspecific reactive hepatitis in aged and infirm people. Am J Dig Dis. 1959;4:389-99.

4. Kim TS, Hur TH, Lim SJ, Bin JH, Hahn SH, Kim SY, et al. A rise and fall in AST and ALT level in nonspecific reactive hepatitis. Clin Exp Pediatr. 2008;51:396-400. 
5. Matoq A, Salahuddin A. Acute Hepatitis and Pancytopenia in Healthy Infant with Adenovirus. Case Rep Pediatr. 2016;2016:8648190.

6. Oh JS, Choi JS, Lee YH, Ko KO, Lim JW, Cheon EJ, et al. The Relationships between Respiratory Virus Infection and Aminotransferase in Children. Pediatr Gastroenterol Hepatol Nutr. 2016;19:243-50.

7. Polakos NK, Cornejo JC, Murray DA, Wright KO, Treanor JJ, Crispe IN, et al. Kupffer cell-dependent hepatitis occurs during influenza infection. Am J Pathol. 2006;168:1169-78; quiz 404-5.

8. Alhammadi AH, Hendaus MA, Kayoum AA. Alteration of liver function due to H1N1 infection: a case report. Clin Exp Gastroenterol. 2013;6:173-5.

9. Eisenhut M, Thorburn K, Ahmed T. Transaminase levels in ventilated children with respiratory syncytial virus bronchiolitis. Intensive Care Med. 2004;30:931-4.

10. Cui HJ, Tong XL, Li P, Hao YX, Chen XG, Li AG, et al. Serum hepatic enzyme manifestations in patients with severe acute respiratory syndrome: retrospective analysis. World J Gastroenterol. 2004;10:1652-5.

11. Kucuk O, Ugras M, Biçer S, Çöl D, Giray T, Erdag G, et al. Hypertransaminasaemia in children with viral gastroenteritis. Infez Med. 2016;24:32-7.

12. Park JY, Ko KO, Lim JW, Cheon EJ, Yoon JM. Increase in Aminotransferase Levels during Urinary Tract Infections in Children. Pediatr Gastroenterol Hepatol Nutr. 2013;16:89-94.

13. Pastor CM, Billiar TR, Losser MR, Payen DM. Liver injury during sepsis. J Crit Care. 1995;10:183-97.

14. Szabo G, Romics L, Jr., Frendl G. Liver in sepsis and systemic inflammatory response syndrome. Clin Liver Dis. 2002;6:1045-66, $\mathrm{x}$.

15. Bechini A, Levi M, Falla A, Ahmad A, Veldhuijzen I, Tiscione E, et al. The role of the general practitioner in the screening and clinical management of chronic viral hepatitis in six EU countries. $J$ Prev Med Hyg. 2016;57:E51-60.

16. Gladman LM, Gorard DA. General practitioner and hospital specialist attitudes to functional gastrointestinal disorders. Aliment Pharmacol Ther. 2003;17:651-4.

17. Tatlow-Golden M, Prihodova L, Gavin B, Cullen W, McNicholas F. What do general practitioners know about ADHD? Attitudes and knowledge among first-contact gatekeepers: systematic narrative review. BMC Fam Pract. 2016;17:129.

18. Burton BK. Inborn Errors of Metabolism in Infancy: A Guide to Diagnosis. Pediatrics. 1998;102:e69.

19. Kang KS. Abnormality on liver function test. Pediatr Gastroenterol Hepatol Nutr. 2013;16:225-32.

20. Vajro P, Maddaluno S, Veropalumbo C. Persistent hypertransaminasemia in asymptomatic children: a stepwise approach. World J Gastroenterol. 2013;19:2740-51 .

\section{Tables}

Table 1. Baseline characteristics 


\begin{tabular}{|c|c|c|}
\hline Characteristics & N (\%), Total=613 & Mean $\pm S D$ \\
\hline Male & 367 (59.9\%) & \\
\hline Female & $246(40.1 \%)$ & \\
\hline Number of relapse $(\mathrm{n}, \%)$ & $17(2.8 \%)$ & \\
\hline \multicolumn{3}{|l|}{ Numbers of siblings } \\
\hline 0 & $121(19.7 \%)$ & \\
\hline 1 & $181(29.5 \%)$ & \\
\hline 2 & $30(4.9 \%)$ & \\
\hline 4 & $2(0.3 \%)$ & \\
\hline Mean age (years) & & $3.49 \pm 5.17$ (range $0 \sim 18$ ) \\
\hline Mean follow up duration (days) & & $37.6 \pm 74.3$ (range 1 486) \\
\hline Mean number of infection & & $1.2 \pm 0.8$ (range $1 \sim 5$ ) \\
\hline \multicolumn{3}{|c|}{ Mean follow-up duration per diagnosis } \\
\hline Respiratory infection (days) & $276(45.0 \%)$ & $37.3 \pm 70.3$ (range 1 486) \\
\hline Gastrointestinal infection (days) & $111(18.1 \%)$ & $39.5 \pm 78.0$ (range $1 \sim 477$ ) \\
\hline Urinary tract infection (days) & $90(14.7 \%)$ & $48.4 \pm 86.3$ (range 1 383) \\
\hline Other febrile disease (days) & $116(18.9 \%)$ & $32.1 \pm 65.5$ (range $1 \sim 425$ ) \\
\hline EBV infection (days) & $37(6.0 \%)$ & $26.4 \pm 38.3$ (range $1 \sim 176$ ) \\
\hline CMV infection (days) & $5(0.8 \%)$ & 133.6 91.2 (range 21 255) \\
\hline \multicolumn{3}{|l|}{ Initial laboratory data } \\
\hline AST (IU/L) & & $171.2 \pm 274.1$ (range $23 \sim 2881$ ) \\
\hline ALT (IU/L) & & $194.9 \pm 316.1$ (range 60 2949) \\
\hline TB (mg/dL) & & $0.56 \pm 0.66$ (range $0.03 \sim 8.69$ ) \\
\hline $\mathrm{DB}(\mathrm{mg} / \mathrm{dL})$ & & $0.23 \pm 0.42$ (range $0 \sim 6.1$ ) \\
\hline Albumin $(\mathrm{g} / \mathrm{dL})$ & & $4.2 \pm 0.5$ (range $2.1 \sim 6.8$ ) \\
\hline GGT (IU/L) & & $84.4 \pm 124.3$ (range 4 1779) \\
\hline ALP (U/L) & & $368.8 \pm 281.5$ (range 38 2732) \\
\hline WBC (/uL) & & $11626.1 \pm 7373.8$ (range $1160 \sim 112,000$ ) \\
\hline Peak laboratory data & & \\
\hline
\end{tabular}




\begin{tabular}{|ll|} 
AST $(\mathrm{IU} / \mathrm{L})$ & $198.1 \pm 300.6$ (range 28 2881) \\
\hline ALT $(\mathrm{IU} / \mathrm{L})$ & $235.1 \pm 355$ (range 60 2949) \\
\hline TB $(\mathrm{mg} / \mathrm{dL})$ & $0.58 \pm 0.77$ (range 0.1 10.8) \\
\hline DB $(\mathrm{mg} / \mathrm{dL})$ & $0.23 \pm 0.44$ (range 0 6.1) \\
\hline Final laboratory data & \\
\hline AST $(\mathrm{IU} / \mathrm{L})$ & $60.6 \pm 49.5$ (range 7 601) \\
\hline ALT $(\mathrm{IU} / \mathrm{L})$ & $72.5 \pm 77.4$ (range 9 818) \\
\hline TB $(\mathrm{mg} / \mathrm{dL})$ & $0.41 \pm 0.40$ (range 0 6.8) \\
\hline DB $(\mathrm{mg} / \mathrm{dL})$ & $0.14 \pm 0.14$ (range 0 1.4) \\
\hline
\end{tabular}

Abbreviations: SD, standard deviation; EBV, Epstein-Barr virus; CMV, cytomegalovirus; AST, aspartate transaminase; ALT, alanine aminotransferase; TB, total bilirubin; DB, direct bilirubin; GGT, gamma glutamyl transferase; ALP, alkaline phosphatase; WBC, white blood cell count

Table 2. Isolated pathogens among 613 subjects 


\begin{tabular}{|lll|}
\hline Pathogen & $\begin{array}{l}\text { Number of positive results } \\
(\mathrm{n}=385)\end{array}$ & Median follow up duration (days, IQR) \\
\hline Rhinovirus & $60(9.8 \%)$ & $13.5(4 \sim 103.3)$ \\
\hline Respiratory syncytial virus & $57(9.3 \%)$ & $12(3.5 \sim 29.5)$ \\
\hline Escherichia coli & $55(9.0 \%)$ & $13(4 \sim 44)$ \\
\hline Epstein-Barr virus & $46(7.5 \%)$ & $13(5.5 \sim 51.5)$ \\
\hline Adenovirus & $30(4.9 \%)$ & $9.5(2.8 \sim 36.8)$ \\
\hline Influenza virus & $21(3.4 \%)$ & $10(1 \sim 51)$ \\
\hline Parainfluenza virus & $18(2.9 \%)$ & $14.5(1 \sim 60.5)$ \\
\hline Metapneumovirus & $16(2.6 \%)$ & $12.5(4 \sim 56.5)$ \\
\hline Cytomegalovirus & $13(2.1 \%)$ & $53(12.5 \sim 160)$ \\
\hline Corona virus & $12(2.0 \%)$ & $11(1.5 \sim 28.8)$ \\
\hline Mycoplasma pneumoniae & $12(2.0 \%)$ & $14(8.8 \sim 45.5)$ \\
\hline Enterovirus & $10(1.6 \%)$ & $7(1 \sim 11)$ \\
\hline Streptococcus & $8(1.3 \%)$ & $12.5(5.5 \sim 87.5)$ \\
\hline Norovirus & $7(1.1 \%)$ & $32(4 \sim 63)$ \\
\hline Other viral infection ${ }^{a}$ & $11(1.8 \%)$ & $9(4 \sim 17)$ \\
\hline Other bacterial infection ${ }^{\text {b }}$ & $9(1.5 \%)$ & $10(7.5 \sim 138.5)$ \\
\hline
\end{tabular}

a Bocavirus $(n=4)$, varicella zoster virus $(n=2)$, sapovirus $(n=2)$, herpes simplex virus $(n=2)$, measles virus $(n=1)$

${ }^{\mathrm{b}}$ Enterobacter $(\mathrm{n}=4)$, Clostridium perfringens $(\mathrm{n}=3)$, Staphylococcus aureus $(\mathrm{n}=1)$, Salmonella $(\mathrm{n}=1)$

Abbreviations: IQR, interquartile range

Table 3. Clinical characteristics according to the follow-up group 


\begin{tabular}{|c|c|c|c|}
\hline & Follow-up group & Loss group & \multirow[t]{2}{*}{$p$-value } \\
\hline & $\mathrm{n}(\%)$ or mean $\pm \mathrm{SD}$ & $\mathrm{n}(\%)$ or mean \pm SD & \\
\hline Number of patients & $442(72.1 \%)$ & $171(27.9 \%)$ & \\
\hline Duration & $50.9 \pm 80.9$ (range 2 486) & 1 & $<0.001$ \\
\hline Age (years) & $3.26 \pm 4.86$ & $4.08 \pm 5.90$ & 0.082 \\
\hline Male & $270(61.1 \%)$ & $97(56.7 \%)$ & 0.358 \\
\hline Female & $127(38.9 \%)$ & $74(61.1 \%)$ & \\
\hline Discontinued by Physician & $352(76.5 \%)$ & $108(23.5 \%)$ & $<0.001$ \\
\hline Patient & $90(58.8 \%)$ & $63(41.2 \%)$ & \\
\hline \multicolumn{4}{|l|}{ Diagnosis } \\
\hline Respiratory infection & $193(69.9 \%)$ & $89(32.2 \%)$ & 0.279 \\
\hline Gastrointestinal infection & $69(62.2 \%)$ & $42(37.8 \%)$ & 0.011 \\
\hline Urinary tract infection & 75 (83.3\%) & $15(16.7 \%)$ & 0.011 \\
\hline Other febrile disease & $86(74.1 \%)$ & $30(25.9 \%)$ & 0.646 \\
\hline EBV infection & $36(97.2 \%)$ & $1(0.3 \%)$ & 0.001 \\
\hline CMV infection & $5(100 \%)$ & $0(0)$ & 0.329 \\
\hline \multicolumn{4}{|l|}{ Physician } \\
\hline Non-GI pediatrician & $317(76.4 \%)$ & $98(23.6 \%)$ & $<0.001$ \\
\hline Pediatric gastroenterologist & $114(90.5 \%)$ & $12(9.5 \%)$ & \\
\hline Pediatric resident & $2(22.2 \%)$ & $7(77.8 \%)$ & \\
\hline Emergency doctor & $9(14.8 \%)$ & $54(85.7 \%)$ & \\
\hline \multicolumn{4}{|l|}{ Initial laboratory data } \\
\hline AST (IU/L) & $199.2 \pm 288.6$ & $85 \pm 59.7$ & $<0.001$ \\
\hline ALT (IU/L) & $226.4 \pm 340.5$ & $99.3 \pm 71.9$ & $<0.001$ \\
\hline TB (mg/dL) & $0.60 \pm 0.73$ & $0.48 \pm 0.41$ & 0.04 \\
\hline $\mathrm{DB}(\mathrm{mg} / \mathrm{dL})$ & $0.25 \pm .46$ & $0.17 \pm 0.19$ & 0.95 \\
\hline Albumin (g/dL) & $4.19 \pm 0.48$ & $4.30 \pm 0.39$ & 0.05 \\
\hline GGT (IU/L) & $91.0 \pm 133.9$ & $51.6 \pm 42.6$ & 0.32 \\
\hline ALP (U/L) & $349.1 \pm 273.1$ & $419.0 \pm 296.7$ & 0.06 \\
\hline
\end{tabular}




\begin{tabular}{|llll|}
\hline WBC $(/ \mathrm{uL})$ & $11871 \pm 5159.7$ & $10992.3 \pm 4737.4$ & 0.191 \\
\hline Peak laboratory data & & & \\
\hline AST $(\mathrm{IU} / \mathrm{L})$ & $236.3 \pm 319.4$ & $85 \pm 59.7$ & $<0.001$ \\
\hline ALT $(\mathrm{IU} / \mathrm{L})$ & $282.1 \pm 384.6$ & $99.4 \pm 71.9$ & $<0.001$ \\
\hline TB $(\mathrm{mg} / \mathrm{dL})$ & $0.63 \pm 0.87$ & $0.48 \pm 0.41$ & 0.032 \\
\hline DB $(\mathrm{mg} / \mathrm{dL})$ & $0.25 \pm 0.49$ & $0.17 \pm 0.19$ & 0.1 \\
\hline Final laboratory data & & & \\
AST $(\mathrm{IU} / \mathrm{L})$ & $50.0 \pm 32.4$ & $85 \pm 59.6$ & $<0.001$ \\
ALT $(\mathrm{IU} / \mathrm{L})$ & $60.6 \pm 68.5$ & $99.3 \pm 71.9$ & $<0.001$ \\
\hline TB $(\mathrm{mg} / \mathrm{dL})$ & $0.38 \pm 0.39$ & $0.48 \pm 0.41$ & 0.009 \\
\hline DB $(\mathrm{mg} / \mathrm{dL})$ & $0.12 \pm 0.11$ & $0.17 \pm 0.19$ & 0.003 \\
\hline
\end{tabular}

Abbreviations: SD, standard deviation; EBV, Epstein-Barr virus; CMV, cytomegalovirus; GI, gastrointestinal; AST, aspartate transaminase; ALT, alanine aminotransferase; TB, total bilirubin; DB, direct bilirubin; GGT, gamma glutamyl transferase; ALP, alkaline phosphatase; WBC, white blood cell count

\section{Figures}
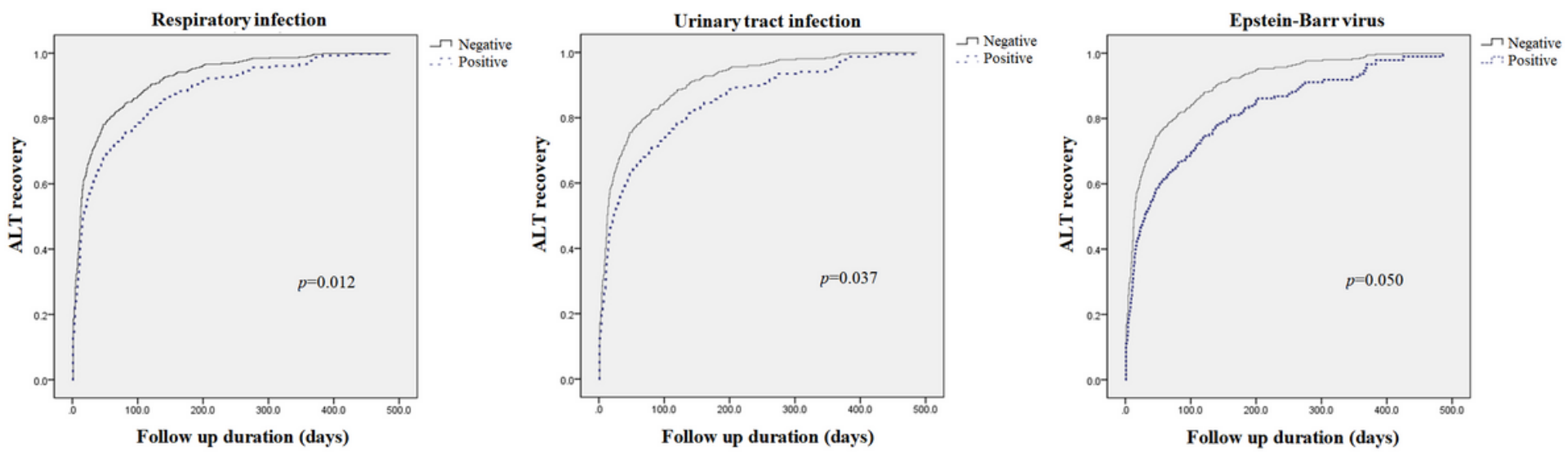

\section{Figure 1}

Kaplan Meier plot for factors related with ALT recovery In the Kaplan-Meier plot, the subjects with respiratory infection, urinary tract infection, and EBV infection showed delayed ALT recovery. Abbreviations ALT, alanine aminotransferase 


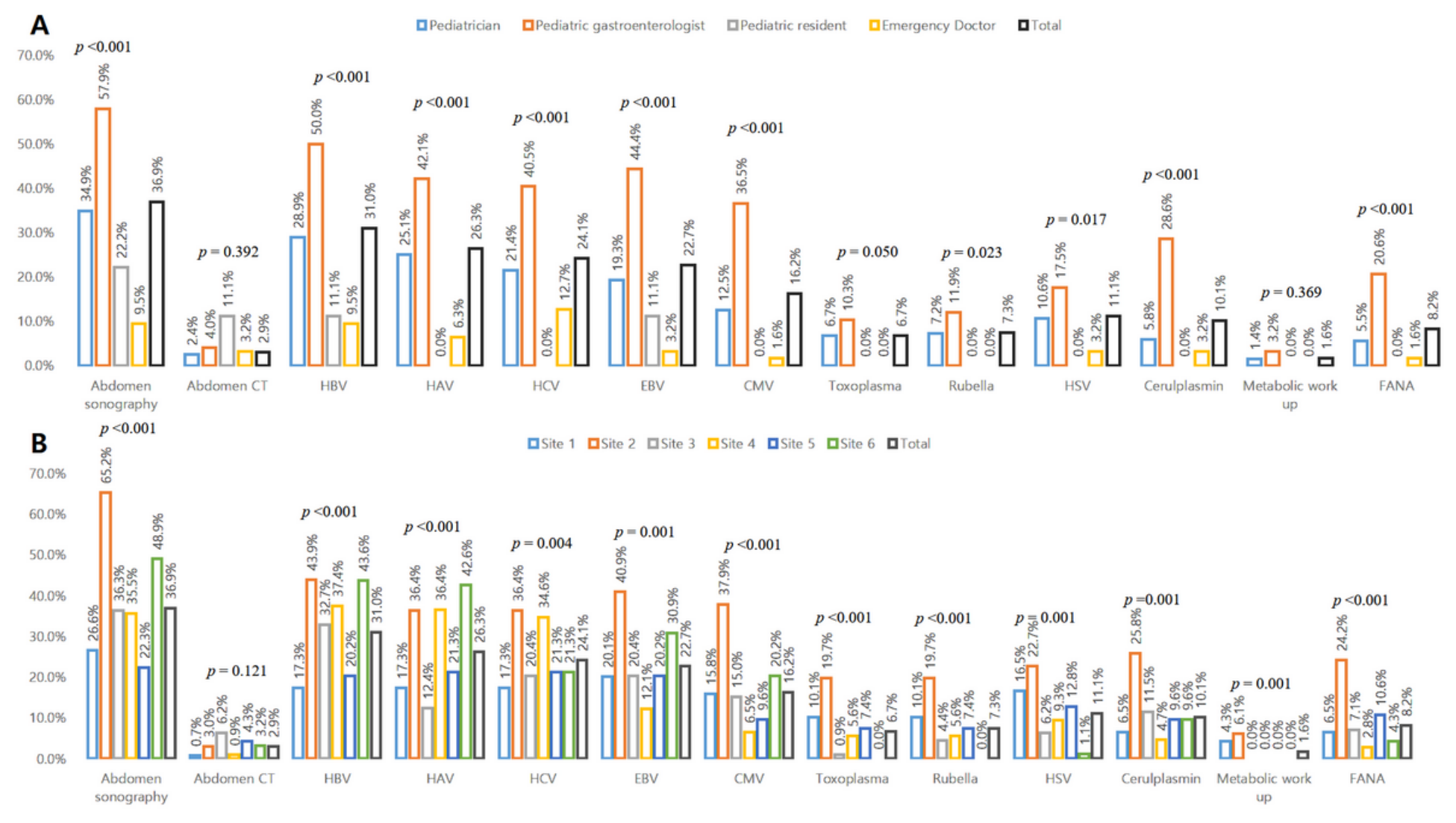

\section{Figure 2}

Diversity of hepatitis workup for abnormal liver function tests in Korean population Figure 2A. Diversity of hepatitis workup among physicians Figure 2B. Diversity of hepatitis workup among hospitals. Abbreviation $\mathrm{CT}$, computed tomography; $\mathrm{HBV}$, hepatitis $B$ virus; $\mathrm{HAV}$, hepatitis A virus; $\mathrm{HCV}$, hepatitis $\mathrm{C}$ virus; EBV, Epstein-Barr virus; CMV, cytomegalovirus; HSV, herpes simplex virus; FANA, fluorescent antinuclear antibody. 